\title{
Novel Corona Virus Disease 2019 (Review on nCOVID-19)
}

\author{
Muhammad Mudassar Shahzad ${ }^{1}$, Syed Hussain ${ }^{2}$, Rahat Rehman ${ }^{3}$, Zawar Hussain ${ }^{3}$, Sana \\ Bashir $^{3}$, Fatima Khalid ${ }^{3}$, Tahir Rafique ${ }^{3}$, Kalsoom Akhtar ${ }^{3}$, Laraib Tahir ${ }^{3}$, Majid \\ Hussain $^{3}$, and Iram Liaquat ${ }^{3}$ \\ ${ }^{1}$ University of Education \\ ${ }^{2}$ Government College University Faisalabad \\ ${ }^{3}$ Affiliation not available
}

June 10, 2020

\begin{abstract}
COVID-19 has now become a global epidemic, prevailing over 213 countries of the world including Pakistan. To date, there have been more than 12000 cases and above 220 deaths reported in Pakistan. The outbreak is caused by a $\beta$-coronavirus called SARS-CoV-2, similar in characteristics to the SARS and MERS-CoV. It shows symptoms like pneumonia and may lead to death. Despite lockdown and possible isolation system, it is spreading rapidly. Lack of precautionary measures, specific vaccine and delayed diagnosis may be the major reasons for its spread. Several researches on COVID-19 have described its various features to extend its knowledge in order to help the scientific world in preparation of vaccine. Current review aimed to cover all essential data such as clinical characteristics, pathology, detailed morphology and structure, antigenicity of COVID-19 virus, role of structural proteins in anti-viral drug development and possible treatments being used. This manuscript would be helpful to select the best possible treatment depending on the availability and condition of the patient. Moreover, further research is needed for assistance in designing a virus-specific drug or vaccine.
\end{abstract}

\section{INTRODUCTION}

Coronaviruses (CoVs) are large, positive-sense, enveloped and single-stranded RNA viruses. They belong to the family; Coronaviridae, subfamily; Coronavirinae, order; Nidovirales, that infect a wide range of host. ${ }^{1}$ They include viruses causing common cold and several animal and birds' coronaviruses, for example "Infectious Bronchitis Virus (IBV), that causes infection in poultry. CoVs characteristically produce gastrointestinal, neurological and respiratory sickness. ${ }^{2}$ The diseases caused by these viruses vary from normal cold to severe/deadly ailments. Coronavirus Study Group of International Committee on Taxonomy of Viruses (ICTV) changed the initial name of virus from "2019-nCoV" to "SARS-CoV-2" as it was discovered to be the sister virus of SARS-CoV i.e. "Severe Acute Respiratory Syndrome Coronavirus. ${ }^{1}$ SARS-CoV-2 is found to be seventh coronavirus that is identified to infect human beings. ${ }^{3}$ It is important to know that the COVID-19 virus (SARS-CoV-2) is not linked with poultry or poultry products. Coronaviruses are divided into four genera; Alpha- $(\alpha)$, Beta- $(\beta)$, Gamma- $(\delta)$ and Delta- $(\gamma)$ coronavirus groups. ${ }^{4}$ The coronavirus in avian Gamma-coronavirus group affects poultry (IBV) and causes respiratory disease in chickens and does not infect humans. ${ }^{5}$ While, COVID-19 virus is in the Beta-coronavirus group together with MERS-CoV (Middle East Respiratory Syndrome Coronavirus) and SARS-CoV that infects mammals. ${ }^{6}$ 


\section{SOURCE OF COVID-19}

Bats are extensively believed to be the reservoir for mammalian (Alpha- and Beta-) coronaviruses. There are around 1,240 different bat species harboring different coronavirus types. SARS-CoV and MERS-CoV arose from a bat reservoir, infected an intermediate host (not identified yet) and then transferred to humans. Probably, the COVID-19 virus originated from bats. Moreover, some initial data shows some viruses, isolated from bats, to be close relatives. ${ }^{5}$ Genomic sequence of COVID-19 virus is relevant and closest to coronaviruses of bat. ${ }^{2}$ However, the genetic data of SARS-CoV-2 shows that it is not manipulated and derived from the backbone of any previously used virus. ${ }^{7}$

\section{HISTORY AND EPIDEMIOLOGY}

Coronaviruses were first revealed in 1960s and have been around for many years, even during 1990s, causing no severe disease in human beings. Though, in 2002-03, a new coronavirus "SARS-CoV" emerged, and then MERS-CoV in 2012 in Saudi Arabia. ${ }^{2}$ In December 2019, a large group of pneumonia cases appeared in Wuhan, Hubei province, China, that were triggered by a newly recognized $\beta$-coronavirus. World Health Organization (WHO) firstly named this as the "2019-novel coronavirus" (2019-nCoV) on 12 January $2020 .{ }^{8}$ Later the name was changed to SARS-CoV-2. Now cases of coronavirus are increasing day by day all around the world except Antarctica, while about above 81,000 cases have been stated in China. ${ }^{9}$ According to WHO, a rise in this pandemic was seen at the end days of January and at the start of February, 2020. ${ }^{10}$ Whereas, a decrease in the rate of these cases was noted by the start of March, 2020. Starting from China, currently it has prevailed globally, over 213 countries or areas of the world, some with minor effects while some with severe deadly conditions like USA, Italy, Spain and France. According to the report of South China Morning Post (SCMP) at June 2, 2020, there are more than 6 million COVID-19 cases worldwide. USA has highest mortality rate i.e. more than 100,000 deaths, followed by UK with more than 39,000 deaths, Italy with above 33,000 deaths and Brazil with more than 30,000 deaths. Coronavirus cases in Pakistan are also continuously increasing. To the writing of this manuscript, there have been 76,398 confirmed COVID-19 cases in Pakistan (Punjab; 27,850, Sindh; 29,647, KP; 10,485, Balochistan; 4514) and 1621 deaths over the country.

The most current data for the study of global disease transmission of this developing pandemic can be found at the WHO COVID-19 Situation Board which use open sources to see the dispersion of this epidemic. ${ }^{11}$

\section{SYMPTOMS OF COVID-19}

Coronavirus infection showed its symptoms in patients after an incubation period of 5 days approximately. ${ }^{12}$ It is noticed and suggested that COVID-19 showed its symptoms in a person within 6 to 41 days approximately with an average of about 14 days. ${ }^{13}$ This said period totally depend on the patients' immune system and its age. ${ }^{14}$ It was rare among patients of age less than 70 years but higher in patients having age of 70 or near it. ${ }^{13}$ The symptoms are high fever (body temperature of $39^{\circ} \mathrm{C}$ ), dry cough, difficulty in breathing and coarse breathing sounds of both lungs ${ }^{15}$ fatigue, severe headache, diarrhoea, lymphopenia, haemoptysis, production of sputum and dyspnea ${ }^{13,16-18}$ (Figure 1).

Chest CT scan of COVID-19 patients showed similar appearance as in the case of pneumonia patients, as well as showed some abnormal properties like "Acute Respiratory Distress Syndrome (ARDS), acute cardiac injury, RNAemia and incidence of grand-glass opacities that causes death. ${ }^{17}$ Whereas, presence of many peripheral ground-glass opacities in subpleural regions were observed in the lungs of some patients as well and ultimately, results in inflammation due to induction of systemic and localized immune response. No clinical effects were seen in patients with inhalation of interferon, instead, it appeared problematic by causing progression in pulmonary opacities. ${ }^{15}$ When patient's chest CT scans were observed, it was also noticed that symptoms of COVID-19 and beta-coronavirus (dry cough, bilateral ground-glass opacities, fever and dyspnea) were similar to each other. ${ }^{17}$ It was also noticed that COVID-19 targets mostly the lower airway and upper respiratory tract and showed symptoms like rhinorrhoea and cause sore throat and sneezing. ${ }^{19}$ While in some cases, presence of infiltrate in upper lob of lung was seen that increases dyspnea with hypoxemia. ${ }^{20}$ 


\section{TRANSMISSION}

It was noticed that the initial cases had exposure with the animals that were infected by COVID-19. Because in Wuhan city, people worked and visited seafood market where they sold live animals. By this way, COVID19 transmitted from animals to human and then, human to human transmission started. ${ }^{21}$ But the main and quick transmission occured through close contact between person to person. This person to person transmission mainly occured through exposure with infected person's respiration droplets during sneezing, coughing and close contact with him/her. An infected person can transmit it into two individuals approximately ${ }^{11}$ (Figure 2).

It can also be transmitted when a person touches an infected surface and then, touches his/her nose, mouth and eyes etc. It was also noticed that the infected person transmits this virus or viral infection to his/her families as well. ${ }^{11}$ Increased transmission rate was also observed in travel related places, workplaces and through import export of infected goods. It was also noted that these droplets do not stay in air and cannot travel more than two meters. It might be transmitted through respiration, skin, feces and urine of the patient. ${ }^{22}$

\section{PATHOLOGICAL CHARACTERISTICS AND EXAMINATION OF COVID-} 19

COVID-19 had same pathological characteristics as of MERS (Middle Eastern respiratory syndrome) and SARS. ${ }^{23}$ Both SARS-CoV and SARS-CoV-2 have ability to infect epithelial cells by fundamental interaction of viral $\mathrm{S}$ proteins with type 2 receptors (angio-tensin converting enzyme) present on cells of human. ${ }^{24}$ That is why, these were assumed to cause similar pathological alterations. In addition to its presence in respiratory system, it may also be present in skin sweat glands, epithelial lining of kidney convoluted tubules and digestive tract. By the examination of infected lungs of COVID-19 patient, it was noticed that there was presence of many fibromyxoid exudation, and some sticky secretions released from alveoli. ${ }^{25}$ According to $\mathrm{Xu}$ et al. (2020) samples of patients' lungs, heart and liver tissues were taken for further pathological examination. ${ }^{26}$ After examination they came to know that alveolar structure was completely diffused and damaged with the presence of cellular fibromyxoid exudation. They also observed a noticeable peeling of pneumocytes and formation of hyaline membrane. Presence of some mucinous secretions in the lungs was also observed ${ }^{22}$ (Figure 3).

Pulmonary edema with formation of hyaline membrane was observed in left lung and it was suggested that this was the symptom of early ARDS. In both lungs of the patient, interstitial mono-nucleate inflammatory infiltrates, submissive by the lymphocytes were present. Viral alterations (prominent nucleoli within the alveolus space, large pneumocytes and cytoplasm with granules) were observed in multinucleated cells. They also noted mild lobular with micro vesicular steatosis in patients' liver samples, indicating that this injury was either due to injury of liver induced by drugs or SARS-CoV-2. They also observed little inflammation in heart tissues but overall no other damage at all. They conducted flow cytometric analysis, prepared peripheral blood and noticed decrease number of T cells i.e. CD8 and CD4 (cluster of differentiation 8 and 4) as well but these cells were super activated as CD38 (CD8 39.4\%) and CD4 (3.47\%). In addition to it, the number of pro-inflammatory CCR6 and Th17 in CD4 type T cells was also increased. Number of cytotoxic granules was maintained by CD8 T cells, having perforin positive cells (31.6\%), granulysin positive cells (64.2\%) and double-positive cells (30.5\%). Due to the over-activation, high toxicity of CD8 T cells and increase in Th17, patients faced severe immune injury and progressive pneumonia ${ }^{26}$ (Figure 4).

In addition to it, greater concentration of pro-inflammatory cytokines like IL1, IL2, IL6, IL7, IL8, IL10, MCP1, MIP1 $\alpha$, GCSF, IP10, Tnf- $\alpha$ and Tnf-beta that boost severity in this disease, were also seen in some severe cases. ${ }^{17}$ According to Chan et al. (2020) the most common feature and critical factor in COVID19 patients is Lymphopenia and it may cause huge severity in infection and increased death rate. ${ }^{27}$ Tian et al. (2020) also presented the histopathological data of some patients who undergo lung lobectomies for adenocarcinoma and observed infection during their surgery. ${ }^{28} \mathrm{Xu}$ et al. (2020) suggested that these 
pathological outcomes not only help to solve intense cases of COVID-19 but can also be used to determine the cause of death and explore new remedial strategies to minify death rate. ${ }^{26}$

\section{ASYMPTOMATIC CARRIER TRANSMISSION OF COVID-19}

It was observed that COVID-19 is transmitted during introductory period when infested persons are slightly ill, and keep on doing normal activities, contributing to the blowout of infection. ${ }^{29,30}$ As stated by a report on "Diamond Princess", out of 1,723, 189 confirmed travelers were asymptomatic (with no visible symptoms), while they were carrier of COVID-19 virus as of February 17, 2020. ${ }^{31}$ In a previous study, a 10-year old boy was reported to be an asymptomatic, with COVID-19 infection, but his chest CT showed abnormalities. ${ }^{27}$ In another study, a 20 year old woman (assumed asymptomatic carrier) travelled from Wuhan to Anyang (China) on January 10, 2020, and met with few people, causing development of COVID-19 infection in them and severe visible symptoms. While she, herself had no symptoms including sore throat and cough. All her tests (RT-PCR, lymphocyte count and C-reactive protein level) were normal till January 28, 2020. But before the day, she had spread virus to five other people (with no travelling history) as an asymptomatic virus carrier. ${ }^{32}$ This indicates that many mild patients and asymptomatic carriers remain unexplored in the society. To study the detailed asymptomatic carrier transmission, an investigation was also carried out on 24 cases in Nanjing, China, describing their clinical characteristics. These infections were separated from nearby contacts showing the transmission capability of asymptomatic COVID-19 virus carriers. These asymptomatic carriers showed no clear symptoms, while were confirmed to be positive for Covid-19 by nucleic acid tests of pharyngeal swab samples. Not a single of these 24 cases had serious pneumonia or expired by COVID-19. All these cases had a chest CT scans. Seven of these carrier individuals were younger (average age; 14 years) as compared to others, with ordinary CT image and no symptoms even during hospitalization. Among these 24 cases, epidemiological history and medical record of one (case 13) was reviewed. Case 13 had a travelling history to Huanggang, Hubei province and was an asymptomatic carrier of virus; however, his nucleic acid test came positive for COVID-19. All his close contacts carried severe infection of COVID19 with clear symptoms such as severe pneumonia, cough, high fever and fatigue etc. and were admitted in hospital. These results direct that mild patients and asymptomatic carriers could also be a source of COVID-19 infection as they can result in transmission from one person to another. It is critical to identify and isolate them to contain the epidemics in far ahead stages. ${ }^{33}$

\section{CLINICAL CHARACTERISTICS}

Among cluster of cases recorded in Wuhan, China,${ }^{13}$ first reported infection caused by SARS-CoV-2 was a serious respiratory illness and has spread throughout the world. ${ }^{34}$ On January 2, 2020, it is examined the clinical features of 41 patients believed to be COVID-19 infected, which included 13 cases of ICU and 28 cases of non-ICU. ${ }^{17}$ On computed tomography imaging, almost all patients had bilateral lung ground glass opacity. The signs initially included fever in most of the infected patients, coughing (76\%), shortness of breath $(55 \%)$, myalgia (44\%), production of thick mucus (28\%), headache (8\%), hemoptysis (5\%) and diarrhea (3\%). In the early stage of the illness, fever was not tested in just one patient. ARDS was developed in $29 \%$ of cases, $12 \%$ had acute heart injury, approximately $7 \%$ had acute kidney injury (AKI) and shock. Chen et al. (2020) confirmed 99 cases of SARS-CoV-2-infected pneumonia on 20 January $2020 .{ }^{35}$ This case series revealed that older males with comorbidities as a result of weaker immune function were the most susceptible to COVID-19 incidence. In this study, the symptoms, complications and treatments were similar to the previous studied record, $31 \%$ were discharged, $11 \%$ were died and $58 \%$ of patients were still hospitalized. Fever, cough and dyspnea are the main clinical manifestations of COVID-19. Gastrointestinal symptoms have a small but important subset. ${ }^{36}$

During the initial outbreak in the province of Hubei, Pan et al. (2020) identified clinical features from 18 January to 28 February 2020 in three seriously affected hospitals that had 97 out of 103 patients acquired respiratory symptoms together with digestive symptoms. ${ }^{37}$ Digestive symptom patients had a slightly longer duration from start of hospital admission than patients without digestive symptom. We found that patients 
with digestive symptoms had a variety of digestive manifestations including diarrhea, lack of appetite, abdominal pain and vomiting. Guan et al. (2020) extracted data from 552 hospitals in China regarding 1099 patients with laboratory-confirmed COVID-19. ${ }^{38}$ The patients' median age was 47 years and $41.9 \%$ were female. Fever (43.8\% after admission and $88.7 \%$ during hospitalization) and cough $(67.8 \%)$ were the most serious symptoms. The uncommon sign was diarrhea $(3.8 \%)$ in patients, $83.2 \%$ of patients on admission had lymphocytopenia. Patients with serious illness were by a mean of 7 years older than those with no severe illness. ${ }^{39}$ In addition, the presence of some coexisting disease was more common among patients with severe illness than among those without serious illness. On treatment, lymphocytopenia was in $83.2 \%$ of patients, thrombocytopenia in $36.2 \%$ and leukopenia in $33.7 \%$. Patients with COVID-19 infection have a lower case of mortality rate than that of MERS and SARS-CoV. The cases in Jiangsu displayed mild or moderate symptoms relative to the cases in Wuhan and no apparent weakness of the gender. ${ }^{40}$ Throughout Wuhan, there was slightly lower number of patients with liver failure and an abnormal CT imaging. Notably, infected patients may be falsely excluded based on 2 consecutively negative respiratory pathogenic nucleic acid test results. ${ }^{41}$ In pregnant women, the clinical features of COVID-19 pneumonia were similar to those identified in non-pregnant adult patients. Findings from this small group of cases suggest that there is currently no evidence for intrauterine infection caused by vertical transmission in women. ${ }^{42}$ Children who had only coronavirus detected were more likely to have underlying chronic diseases than children who had dual respiratory infections. This list may not be all-inclusive, medical warning signs include recurrent chest pain or strain, frustration or failure to excite and bluish lips or face. ${ }^{12}$

\section{STRUCTURE OF CORONA VIRUS}

The name $\mathrm{CoV}$ is a derivative of the Latin word corona that means crown. This is because of the characteristic structure of the virus whereby surface projections on the viral envelope give it a similar appearance to a crown. ${ }^{43}$

\subsection{Morphology of corona virus}

Enveloped, pleomorphic or spherical coronaviruses are 150 to $160 \mathrm{~nm}$ in size, associated with positive single stranded RNA, with 5'-Cap structure and 3'-poly-A tail, ${ }^{44}$ which acts itself as an mRNA, un-segmented, nucleoprotein, capsid, matrix, and S-protein. ${ }^{45}$ Nucleocapsid protein $(\mathrm{N})$, membrane glycoprotein $(\mathrm{M})$, and spike glycoprotein (S) are important viral proteins that are necessary for COVID-19 assembly and infection. COVID-19 differs from other coronaviruses by encoding an extra glycoprotein with properties of acetyl esterase and hemagglutination (HE). ${ }^{46}$ For coronaviruses in all four genera, coronavirus entry into host cells is directed by an envelope-anchored spike protein. ${ }^{47}$

The virus is a single-stranded positive-sense RNA virus with a genome of around $30 \mathrm{~kb}$ in length. The coronavirus RNA genome (ranging from 26 to $32 \mathrm{~kb}$ ) is the largest of all RNA viruses and the viral particle has a diameter of about $125 \mathrm{~nm} .{ }^{48}$ Due to this, they are the largest known RNA viruses. ${ }^{49}$ The RNA genome codes for both structural proteins (SPs) and non-structural proteins (NSPs). All known CoVs share a similar structure made of four main structural proteins: spike (S), membrane (M), envelope (E), and nucleocapsid $(\mathrm{N})$ proteins. Both structural (SP) and non-structural (NSP) proteins are coded by RNA genome. The S-protein help in binding to the host receptors, M protein helps to form proper shape of the virion particles and in binding to nucleocapsid, E-protein perform an important role in the assembly and release of particles while N-protein help in binding of the genome to a replication transcription complex which is essential for the genomic material replication. Among the structural proteins, four protein has special importance namely spike (S), envelope (E), membrane $(\mathrm{M})$, and nucleocapsid $(\mathrm{N})$. Within the viral membrane $\mathrm{S}$, E, and $\mathrm{M}$ proteins are present. The proteins $\mathrm{M}$ and $\mathrm{E}$ are involved in viral assembly, while the $\mathrm{N}$ protein is necessary for assembly of the RNA genome.The S protein, a surface located trimeric glycoprotein of CoVs, plays a functional role in viral entry into host cells, viral infection and pathogenesis The S protein, a trimeric $\mathrm{CoV}$ glycoprotein found on the surface, plays an important role in viral entry into the host cells, viral infection and 
pathogenesis. ${ }^{50}$ Coronavirus recognizes the receptor on the target cell through the $\mathrm{S}$ protein on its surface and enters into the cell, then allow the infection to occur (Figure 5).

\subsection{Spike protein}

The $\mathrm{S}$ protein is the common target when designing vaccines based on neutralizing antibodies. It contains a receptor binding domain (S-RBD) in the S1 subunit, which mediates receptor binding and membrane fusion. ${ }^{8,51}$ The spike is in very two various forms: pre-fusion (the form on mature virions) and post-fusion (the form that has been completed after membrane fusion). The structure of the pre-fusion form is a homotrimer, with three receptor-binding S1 heads sitting on top of a trimeric membrane-fusion S2 stalk. ${ }^{52-58}$ The structure of the post-fusion form is a coiled-coil structure, containing S2 only. ${ }^{59,60}$ The pre-fusion form is a metastable state: due to the structural constraints imposed by S1, S2 is prevented from transitioning to the post-fusion structure. However, the spike is sequentially cleaved at two sites during cell entry by host proteases: first at the S1/S2 boundary (i.e., S1/S2 site) and second within S2. ${ }^{61,62} \mathrm{~S} 1$ dissociates from S2 after the cleavages, allowing S2 to transition to the post-fusion structure. The transition from pre-fusion to post-fusion phase is irreversible and this process is thus strictly controlled throughout the entry process. ${ }^{47}$ The spike surface glycoprotein plays a key role in its attachment to host cells and can be further cleaved by host proteases into an N-terminal S1 subunit and a membrane-bound C-terminal S2 region The spike surface glycoprotein perform an important function in its binding to host cells and can be further split into an N-terminal S1 subunit and a membrane bound C-terminal S2 region by host proteases. ${ }^{55}$

\subsection{Nucleocapsid (N) protein of virus}

The N-protein in coronaviruses is the most abundant, conservative protein; hence, it is also used as a diagnostic antigen. Our analysis revealed that the antigenicity of the COOH terminus of the SARS-CoV N protein is higher than that of the NH2 terminus, and that the former N protein fragment may have the same antigenicity as that seen with the full length $\mathrm{N}$ protein. ${ }^{63}$ Antibodies may cross react with the COVID -19 that are produced against the $\mathrm{N}$ protein of SARS-CoV ${ }^{64}$ The heterophilic antibodies of SARS-CoV may not provide cross protection to COVID-19. Nevertheless, they can be used for diagnostic purposes. Another important function of SARS-CoV N protein is its ability to circumvent host immune response as an RNA viral suppressor protein (VSR). ${ }^{65}$ The VSRs suppress the RNA at the pre-dicer or post-dicer level to control the host defensive mechanism to establish infection ${ }^{66}$ (Figure 6).

\subsection{SARS-CoV-2 spike glycoprotein is responsible for antigenicity}

Cell entry is one of the most crucial components of cross-species transmission, particularly, for the betacronaviruses. All CoVs cipher a surface glycoprotein, spike that comes in contact with the receptor of the host cell and mediates viral entry. ${ }^{47}$ In case of beta-coronaviruses, the only region which is present in spike proteins called the receptor- binding domain (RBD) interacts with the host cell receptor. When it binds with the receptor the spike, is being cleaved by an adjacent host protease and releases the spike fusion peptide, and aid in virus entry. ${ }^{67-70}$

\subsection{Viral entry- triggers cascade of immunological responses}

SARS COV binding to ACE2 receptors of pneumocytes in lungs triggers inflammation in lower respiratory tract. ${ }^{71}$ It has been shown that when SARS spike proteins bind to the ACE2 receptors the complex thus formed is proteolytically processed by TMPRSS2 (Type II transmemberane protease) which leads to cleavage of ACE2 and spike proteins are activated (Figure 7b). ${ }^{72,73}$ It has been suggested that cells in which ACE2 and TMPRSS2 co-exists, such cells are more susceptible to SARS COV infections. ${ }^{74}$ Clinical presentation suggest that SARS COV-2 also requires ACE2 and TMPRSS2 for entry into the host cells. ${ }^{51}$ Entry of virus and cell infection triggers the immune response and antigen- presenting cells (APC) initiate a set of 
Immunological reactions. Primarily APC perform two functions (1) $\mathrm{CD}_{4}{ }^{+}-\mathrm{T}$ - helper cells (Th 1) combat foreign antigen particle (2) secreting inter-leukin-12 for further stimulation of Th1 cells. $\mathrm{CD}_{8}{ }^{+}$-T-killer cells (TK) are stimulated by Th1 cells that will target any of the cell containing foreign antigen and eventually activated Th 1 cells trigger B- cells to generate antigen specific antibodies. ${ }^{75}$

\subsection{Potent receptor for SARS COV-2- ACE2}

Coronaviruses used to enter host cell by two distinct routes, ${ }^{73}$ the first possible route is cell mediated endocytosis. The surface spike $\mathrm{S}$ glycoproteins has been accepted as key determinant, for coronaviruses entry, with S1 domain mediating the binding of receptor and domain S2 is responsible for membrane fusion of cell. ${ }^{58}$ The second possible route is that spike protein $\mathrm{S}$ is being cleaved by S-activating protease coexpressed with the host cell receptor, thereby inducing the direct fusion of cellular and viral membrane. ${ }^{67}$

\section{TRANSMEMBRANE SPIKE (S) GLYCOPROTEINS}

\subsection{Structure}

Spike proteins S are present on surface of coronaviruses and facilitate in viral entry for infection. ${ }^{76}$ The entry of cronavirus into the host cells is mediated by spike glycoproteins (S) that form homo-trimers that extend above the surface of virus ${ }^{77}$ (Figure 8a). S consists of two functional subunits which are present for attachment with the receptor of host cell (S1 subunit) and fusion of the viral and cellular membranes (S2 subunit). For most CoVs, at the boundary between the S1 and S2 subunits, $\mathrm{S}$ is cleaved which remain non-covalently bound in the prefusion conformation. ${ }^{52,54,62,70,78-80}$ The diatal S1 unit consists of receptor binding domains and participates in the stability of the prefusion state of the membrane-anchored S2 subunit which consists of the fusion machinery ${ }^{52,54,55,58,60,81,82}$ (Figure $8 \mathrm{~b}$ ).

Trimers are being formed by spike molecules, which must be cleaved by cellular proteases, so that fusion peptide can aid in fusion of viral membrane with infected cells. The proteases produce two subunits S1 and S2 from the spike molecule, and S1 subunit consists of critical RBD receptor binding domains to bind with ACE2 of host cells. The receptor binding motif which is present in receptor binding domain forms direct contact with ACE2. Several others critical structures of spike proteins including Central Helix (CH) and heptad repeat 1 and 2 (HR1 and HR2) domains also help in fusion of virus with host cells ${ }^{51}$ (Figure 9).

\subsection{Spike proteins and conformational changes}

For all CoVs, the so-called $\mathrm{S}_{2}$ site located immediately upstream of the fusion peptide is being used for further cleavage of $\mathrm{S} .{ }^{6,83}$ This cleavage has been reported to trigger conformational changes that activate the proteins for membrane fusion via extensive irreversible changes. ${ }^{60-62,70}$ Consequently, entry of coronavirus into susceptible cells is a complicated activity that requires coherent action of receptor binding and proteolytic processing of the $\mathrm{S}$ protein to enhance virus-cell fusion. After getting entry into the host cell, usually through contact with contaminated surfaces and aerosolized viral particles, the virus needs to undergo biological cycle. Spike proteins which are encoded by $\mathrm{S}$ gene on open reading frame on viral genome need to interact with viral receptors on the surface of host cells. Coronavirus spike binds with angiotensin-converting enzyme-2 (ACE2 ), which are present in epithelial cells of the lungs. ${ }^{84,85}$ This is one of the major reasons why coronaviruses often cause respiratory disorders. ACE-2 receptors may also be highly expressed in intestinal tissues leading to diarrhea, as detected in few cases of SARS COV-2 patients. ${ }^{86}$ After binding to ACE-2 receptors via the RBD of the S1 and S2 domains of the spike protein, the viral envelope fuses with the host cell membrane and is further internalized. Genetic material approximately of the size 20-32 kb, is released into the cytoplasm for replication $^{51}$ (Figure 10).

\subsection{Escaping from host immune response}

It has been suggested previously that coronaviruses use glycan shielding and conformational masking to prevent identification by the immunity of host cells. ${ }^{53,87,88}$ 


\subsection{Structural proteins S are important considerations for anti-viral drug de- velopment}

Structural proteins are one of the most important targets for vaccines or anti-viral drug development because of their functional role in fusion and entry of virus in host cells. ${ }^{89}$ Because coronavirus spike glycoproteins are exposed on surface and mediate the virus entry into host cells, it is the main focus of vaccine design by neutralizing antibodies upon infection and proper folding is accomplished by N-linked glycans that are present on $\mathrm{S}$ trimmers ${ }^{90}$ and for modulating accessibility to host proteases and neutralizing antibodies. ${ }^{53,87,88,91}$

\section{TREATMENT}

To date, there is no well-known, effective \& pharmacologically proved treatment of SARS-CoV-2. Different antiviral drugs were administered for $90 \%$ of COVID-19 patients in different reports. ${ }^{17,92,93}$ Although, major antiviral treatments that were proposed, include lopinavir/ritonavir, ${ }^{17,92-95}$ oseltamivir, ganciclovir, ${ }^{17,92,93}$ Arbidol (umifenovir), remdesivir, favipiravir, ribavirin, ${ }^{96}$ chloroquine, ${ }^{96-100}$ hydroxychloroquine,${ }^{97,100,101}$ and alpha-interferon. ${ }^{96}$ Plasma transfusion was also reported for the treatment of corona virus. ${ }^{92}$ This literature review is subjected to compare the efficacy of major antiviral drugs against the treatment of COVID-19 and choose the most appropriate one to treat SARS-CoV-2.

\subsection{Treatment through convalescent plasma}

Immunoglobulins or convalescent plasma had been used as a last weapon to treat viral infections in past. Studies have revealed that the use of convalescent plasma improves the health of patients as well as lowers the rate of mortality than those who are not treated with immunoglobulins. ${ }^{102-104}$ The use of convalescent plasma was administered in 2014 by WHO for the treatment of Ebola-virus disease. ${ }^{105}$ In 2015, immunoglobulins were also used for the treatment of MERS-CoV. ${ }^{106}$ By using immunoglobulins, immune response is developed in patients by 10 to 14 days. ${ }^{102}$ For the treatment of SARS-CoV-2 pneumonia, convalescent plasma was taken from recovered patients of COVID-19 and transfused in infected patients of SARS-CoV-2. ${ }^{92}$

\subsection{Treatment through drugs}

Ritonavir/lopinavir is a drug used against HIV infection. ${ }^{107}$ Lim et al. (2020) reported that ritonavir/lopinavir was found effective against the SARS-CoV-2 pneumonia. ${ }^{95}$ In clinical experiments as well as in vitro studies, ritonavir/lopinavir found to have anti-SARS-CoV activity. Another antiviral drug ribavirin was found effective by mono-therapy against SARS. Combined therapy with ribavirin and ritonavir/lopinavir; lowers the risk of ARDS and even death. ${ }^{108}$ While on the other hand, Cao et al. (2020) reported that no significant benefits were observed by the use of ritonavir/lopinavir with standard care in adult patients having acute COVID-19 infection. ${ }^{94}$

RNA-dependent RNA polymerase inhibitor known as favipiravir was suggested for the treatment of nCoV19 on February 15, 2020 in China. It has anti-viral activity against influenza virus. It also has potential action against SARS-CoV-2 that is RNA virus like influenza virus. Favipiravir blocks the replication process of various viruses by inhibiting RNA polymerase activity. ${ }^{109}$ It inhibits replication of alpha-, arena-, flavi-, filo-, noro-, bunya-, and several other RNA-viruses. ${ }^{110}$ Now favipiravir is under the clinical trials to treat SARS-CoV-2 pneumonia by the Clinical Medical Research Center of the National Infectious Diseases and the Third People's Hospital of Shenzhen on February 14, 2020. Now results from a group of 80 patients in China (including control and experimental groups) revealed that anti-viral action of favipiravir was better than that of ritonavir/lopinavir. From clinical trials till now, favipiravir showed no or fewer adverse reactions in treatment group as compared to ritonavir/lopinavir group. ${ }^{111}$

Another broad-spectrum antiviral drug $\alpha \lambda \pi \eta \alpha-\iota \nu \tau \varepsilon \rho \varphi \varepsilon \rho o \nu(I \Phi N-\alpha)$ is used for the treatment of hepatitis. ${ }^{112}$ IFN- $\alpha$ can be used to stop the replication of SARS-CoV as it gave positive results in vitro. ${ }^{96}$ Influenza antiviral drug, arbidol effectively retards the SARS-CoV-2 infection in vitro. ${ }^{113}$ 
Remdesivir, like IFN- $\alpha$ is also an anti-viral drug that was found to inhibit RNA polymerase activity in vitro against various RNA viruses. ${ }^{114}$ Sheahan et al. (2020) reported that animal research on mice showed that remdesivir was effective to lessen the viral attack on lung tissues of mice having MERS-associated$\mathrm{CoV}$ infection. ${ }^{115}$ It also reduces pathological damage to lungs and improves the functioning of lungs. It was revealed that anti-viral drug remdesivir potentially stops the SARS-CoV-2 infection. ${ }^{116,117}$ It is also reported that combined therapy of chloroquine and remdesivir gives high effectiveness to control nCoV-19 in vitro. ${ }^{118}$ Studies on rhesus macaque model also showed positive results against MERS-CoV infection. ${ }^{119}$ But further pre-clinical trials should be conducted for effective and safe use of remdesivir to treat COVID-19 infection..$^{96,120}$

Chloroquine and hydroxychloroquine (analogue drug of chloroquine), both have anti-malarial as well as broad spectrum anti-viral characteristics. ${ }^{99,100,121}$ These drugs have good safety profile for clinical use as well as economically cheap..$^{97,99}$ The in vitro anti-viral activity of chloroquine and hydroxychloroquine has been reported in different publications. ${ }^{118,122-125}$ Both hydroxychloroquine and chloroquine were found to inhibit the growth of several viruses (including the SARS-associated coronavirus and MERS associated coronavirus) in cell culture. This inhibition is achieved by interfering the process of glycosylation of SARS-CoV receptors present on cell surface as well as reducing the replication of virus. ${ }^{97,121,126,127-129}$ In the light of previous knowledge about these dual nature drugs (anti-malarial as well as anti-viral), scientists are compelled to work on their efficacy against SARS-CoV-2. ${ }^{97,99}$

As this virus emerged from China so most of the work is reported from patients in China. It was found that chloroquine had potential benefits against SARS-CoV-2 in Chinese patients to treat the viral infection. ${ }^{99}$ Wang et al. (2020) also reported that SARS-associated-CoV-2 infection was found blocked, by the use of chloroquine in vitro. ${ }^{116}$ Combined therapy with chloroquine has significant role in antiviral treatments. ${ }^{127}$ It is also observed that hydroxychloroquine has excellent safety profile than that of chloroquine. ${ }^{130}$ French scientists confirmed that combined therapy of hydroxychloroquine and azithromycin proved more efficient for the elimination of SARS-CoV-2. ${ }^{101}$ The toxic and therapeutic dose of hydroxychloroquine and chloroquine has a very narrow margin and slight over-dose may cause cardiovascular problems. ${ }^{131}$ Therefore, the use of hydroxychloroquine and chloroquine should be under strict rules and there should be no recommendations for self-treatment. Two types of salts in chloroquine (phosphate and sulfate) play major role in its antiviral activity. ${ }^{100}$ Results of more than 100 COVID-19 patients from different hospitals of China were collected and it was found that chloroquine phosphate plays a crucial role in the treatment of patients according to the news briefing. In the conference of regulatory and government authorities held on February 15, 2020, there was an agreement taken that chloroquine phosphate has a significant role in the treatment of COVID-19.

Recently, Gao et al. (2020) and Multicenter collaboration group of Department of Science and Technology of Guangdong Province and Health Commission of Guangdong reported that 500mg twice daily administration of chloroquine for the treatment of SARS-CoV-2 pneumonia cause reduction in the duration of stay in hospital for treatment. So, chloroquine was included in the guidelines to treat and prevent this life threatening SARS-CoV-2 pneumonia. ${ }^{99}$ To meet the urgent need of treatment for life threatening corona virus-19, hydroxychloroquine and chloroquine are the drugs that would be recommended to prevent SARS-CoV-2 pneumonia. ${ }^{97,99}$ In the light of previous experiments in respect to antiviral research with chloroquine and hydroxychloroquine, the scientific community of the whole world should consider this useful information to prevent COVID-19.

\subsection{Care}

Risk of infection from above described virus can be reduced to maximum by care and adopting following precautionary measures. Wash hands with soap and use sanitizer regularly. Avoid handshake and close contact with infected person and don't visit outside, crowded places and gatherings. Cover your mouth with mask. Cough and sneeze under elbow to protect others.

\section{SUMMARY}

This review sum-ups the current and actual findings of COVID-19 infection along with pathogen structure, 
transmission, characteristics, antigenicity, treatments and extensive care. The most common symptoms and clinical features of this infection were also explained. Only biopsy report for the pathological characteristics of this infection was studied and reported in this review but autopsy report will be added in future work by further analysis. As this infection is spreading all over the world so rapidly. WHO issued health emergency for public and reported current confirmed cases, overall death rate regarding this infection minute by minute. Currently no vaccine and specific treatments have been discovered for this dangerous infection. But the best strategy to overcome this infection is to control the source of infection, protecting people, decreasing the transmission by avoiding gatherings and following social distancing instructions. Infected people should be quickly traced, isolated from others and treated timely. People who were in close contact with the infected ones should be suggested for quarantine. Healthy people should be alert and sensible to protect themselves by staying at home and follow precautionary measures as well. Authorities should strictly address people to stay at home, avoid close contact and gatherings. Institutions should be closed further. These precautionary measures will be very helpful to overcome this worldwide pandemic. Further research will be focused on the alternative treatments and tests for early diagnostics, development of vaccine and useful drugs to control this pandemic rapidly.

\section{CONFLICT OF INTEREST}

All the authors are volunteer for this review without any payment from any organization.

\section{References}

1. Gorbalenya AE, Baker SC, Baric RS, et al. Severe acute respiratory syndrome-related coronavirus-The species and its viruses, a statement of the Coronavirus Study Group. BioRxiv. 2020.

2. Ng LF, Hiscox JA. Coronaviruses in animals and humans. BMJ.2020;m634.

3. Andersen KG, Rambaut A, Lipkin WI, et al. The proximal origin of SARS-CoV-2. Nat Med . 2020;1-3.

4. Gonzaalez JM, Gomez-Puertas P, Cavanagh D, Gorbalenya AE, Enjuanes L. A comparative sequence analysis to revise the current taxonomy of the family Coronaviridae. Archives Virol. 2003;148:2207-35.

5. Jackwood MW. What we know about avian corona virus infectious bronchitis virus (IBV) in poultry and how that knowledge relates to the virus causing COVID-19 in humans. Amer Assoc Aman Pathol.2020.

6. Swayne DE, Suarez DL, Spackman E, et al. Domestic poultry and SARS coronavirus, southern China. Emer Infect Dis. 2004;10:914.

7. Almazan F, Sola I, Zuniga S, et al. Coronavirus reverse genetic systems: Infectious clones and replicons. Virus Res.2014;189:262-270.

8. Lu R, Zhao X, Li J, et al. Genomic characterization and epidemiology of 2019 novel coronavirus: implications for virus origins and receptor binding. Lancet. 2020;395:565-574.

9. Kenneth McIntosh, MD. Coronavirus disease 2019 (COVID-19). 2020. https://www.who.int/dg/speeches/detail/who-director-general-s-opening-remarks-at-the-media-briefing-oncovid-19 - 24-february-2020 (26 February 2020, date last accessed).

10. WHO (World Health Organization). Coronavirus disease 2019 (COVID-19). 2020. https://www.who.int/dg/speeches/detail/who-director-general-s-opening-remarks-at-the-media-briefing-oncovid-19-24-february-2020 (Accessed on February 26, 2020).

11. Cascella M, Rajnik M, Cuomo A, Dulebohn SC, Napoli RD, et al.Features, Evaluation and Treatment Coronavirus (COVID-19). Stat Pearls Publishing, Treasure Island FL. 2020.

12. Li Q, Guan X, Wu P, Wang X, Zhou L, Tong Y, et al. Early transmission dynamics in Wuhan, China, of novel corona virus-infected pneumonia. N Engl J Med. 2020;382:1199-1207. 
13. Wang W, Tang J, Wei F, et al. Updated understanding of the outbreak of 2019 novel corona virus (2019-nCoV) in Wuhan, China. J Med Virol. 2020;92:441-447.

14. Rothan HA and Byrareddy SN. The epidemiology and pathogenesis of coronavirus disease (COVID-19) Outbreak. J Autoimmuni.2020;109:102433.

15. Lei J, Li J, Li X, Qi X, et al. CT imaging of the 2019 novel corona virus (2019-nCoV) pneumonia. Radiology. 2020;295:18.

16. Ren LL, Wang YM, Wu ZQ, Xiang ZC, Guo L, Xu T, et al.Identification of a novel corona virus causing severe pneumonia in human: a descriptive study. Chinese Med J. 2020;1.

17. Huang C, Wang Y, Li X, Ren L, Zhao J, Hu Y, et al. Clinical features of patients infected with 2019 novel corona virus in Wuhan, China.Lancet. 2020;395:497-506.

18. Carlos WG, Cruz CSD, Cao B, Pasnick S, Jamil S, et al. Novel wuhan (2019-nCoV) corona virus. Am J Respir Crit Care Med.2020;201:7-8.

19. Assiri A, Al-Tawfifiq JA, Al-Rabeeah AA, Al-Rabiah FA, Al-Hajjar S, Al Barrak A, et al. Epidemiological, demographic, and clinical characteristics of 47 cases of Middle East respiratory syndrome corona virus disease from Saudi Arabia: a descriptive study. Lancet Infect Dis. 2013;13:752-761.

20. Phan LT, Nguyen TV, Luong QC, Nguyen TV, Nguyen HT, Le HQ, et al. Importation and human-tohuman transmission of a novel corona virus in Vietnam. N Engl J Med. 2020;382:872-874.

21. Hassan S, Sheikh FN, Jamal S, et al. Coronavirus (COVID-19): A Review of Clinical Features, Diagnosis, and Treatment. Cureus.2020;123:7355.

22. Mao Y, Wei L, Junping W, Gang C, et al. Clinical and pathological characteristics of 2019 novel coronavirus disease (COVID-19): a systematic review. Fujian Acad of Med Sci. 2020;31.

23. Ng DL, Al-Hosani F, Keating MK, et al. Clinicopathologic, immunohistochemical, and ultrastructural findings of a fatal case of Middle East respiratory syndrome coronavirus infection in the United Arab Emirates. Am J Pathol. 2016;186:652-58.

24. Shi H, Han X, Jiang N, et al. Radiological findings from 81 patients with COVID-19 pneumonia in Wuhan, China: a descriptive study [Published Online February 24, 2020]. Lancet Infect Dis.2020;20:425434.

25. Liu Qian WR, Guoqiang Q, Yunyun W, et al. A report on the general observation of the necropsy of a newly developed coronavirus pneumonia. Fa Yi Xue Za Zhi. 2020;1004-5619.

26. Xu Z, Shi L, Wang Y, Zhang J, Huang L, Zhang C, et al.Pathological findings of COVID-19 associated with acute respiratory distress syndrome. Lancet Res Med. 2020;8:420-422.

27. Chan JFW, Yuan S, Kok KH, et al. A familial cluster of pneumonia associated with the 2019 novel coronavirus indicating person-to-person transmission: a study of a family cluster.Lancet. 2020;395:514-523.

28. Tian S, Hu W, Niu L, Liu H, Xu H, Xiao S, et al. Pulmonary Pathology of Early Phase 2019 Novel Coronavirus (COVID-19) Pneumonia in two Patients with Lung Cancer. Preprints. 2020.

29. Heymann DL, Shindo N. COVID-19: what is next for public health? Lancet. 2020;395:542-545.

30. Zou L, Ruan F, Huang M, et al. SARS-CoV-2 viral load in upper respiratory specimens of infected patients. $N$ Eng J Med. 2020;382:1177-1179.

31. Wikipedia. Diamond Princess (ship). https://en.wikipedia.org/wiki/ Diamond_Princess_(ship) 2020.

32. Bai Y, Yao L, Wei T, et al. Presumed asymptomatic carrier transmission of COVID-19. JAMA. 2020. 
33. Hu Z, Song C, Xu C, et al. Clinical characteristics of 24 asymptomatic infections with COVID-19 screened among close contacts in Nanjing, China. Sci China Life Sci. 2020;1-6.

34. Sabino-Silva R, Jardim ACG, Siqueira WL. Coronavirus COVID-19 impacts to dentistry and potential salivary diagnosis. Clin Oral Investig. 2020;1-3.

35. Chen N, Zhou M, Dong X, et al. Epidemiological and clinical characteristics of 99 cases of 2019 novel coronavirus pneumonia in Wuhan, China: a descriptive study. Lancet. 2020;395:507-513.

36. Jiang F, Deng L, Zhang L, et al. Review of the clinical characteristics of coronavirus disease 2019 (COVID-19). J Gener Intern Med. 2020;1-5.

37. Pan L, Mu M, Ren HG, Yang P, Sun Y, Wang R. Clinical characteristics of COVID-19 patients with digestive symptoms in Hubei, China: a descriptive, cross-sectional, multicenter study. Am J Gastroenterol . $2020 ; 20$.

38. Guan WJ, Ni ZY, Hu Y, Liang WH, Ou CQ, He JX, et al. Clinical characteristics of coronavirus disease 2019 in China. N Engl J Med. 2020.

39. Sun P, Qie S, Liu Z, Ren J, Li K, Xi J. Clinical characteristics of 50466 hospitalized patients with 2019-nCoV infection. J med virology. 2020.

40. Wu J, Liu J, Zhao X, Liu C, Wang W, Wang D, et al. Clinical Characteristics of Imported Cases of Coronavirus Disease 2019 (COVID-19) in Jiangsu Province: A Multicenter Descriptive Study. Clinic Infect Dis. 2020.

41. Du Z, Wang L, Cauchemez S, et al. Risk for transportation of 2019 novel coronavirus disease from Wuhan to other cities in China.Emerging Infect Dis. 2020;26.

42. Chen H, Guo J, Wang C, Luo F, Yu X, Zhang W, et al. Clinical characteristics and intrauterine vertical transmission potential of COVID-19 infection in nine pregnant women: a retrospective review of medical records. Lancet. 2020;395:809-815.

43. Perlman S, Netland J. Coronaviruses post-SARS: update on replication and pathogenesis. Nat Rev Microbiol. 2009;7:439-450.

44. Chen Y, Liu Q, Guo D, et al. Emerging coronaviruses: genome structure, replication, and pathogenesis. $J$ Med Virol.2020;2:418-423.

45. Chan JFW, To KKW, Tse H, Jin DY, Yuen KY, et al. Interspecies transmission and emergence of novel viruses: lessons from bats and birds. Trends Microbiol. 2013;21:544-555.

46. Perlman S. Another decade, another coronavirus. N Eng J Med.2020;382:760-762.

46. Wu F, Zhao S, Yu B, Chen YM, Wang W, Hu Y, et al. Complete genome characterization of a novel coronavirus associated with severe human respiratory disease in Wuhan. China. bioRxiv. 2020.

47. Li F. Structure, function, and evolution of coronavirus spike proteins. Annu Rev Virol. 2016; 3:237-261.

48. Ji W, Wang W, Zhao X, Zai J, Li X, et al. Cross-species transmission of the newly identified coronavirus 2019-nCoV. J Med Virol. 2020;92:433-440.

49. Madhugiri R, Fricke M, Marz M, Ziebuhr J, et al. Coronavirus cis-acting RNA elements. In Adv Virus Res. 2016;96:127-163.

50. Song Z, Xu Y, Bao L, Zhang L, Yu P, Qu Y, Qin C, et al. From SARS to MERS, thrusting coronaviruses into the spotlight. Virus.2019;11:59.

51. Zhou P, Yang XL, Wang XG, Hu B, Zhang L, Zhang W, et al. A pneumonia outbreak associated with a new coronavirus of probable bat origin. Nature. 2020;579:270-273. 
52. Walls AC, Tortorici MA, Frenz B, Snijder J, Li W, Rey FA, et al. Glycan shield and epitope masking of a coronavirus spike protein observed by cryo-electron microscopy. Nat Struct Mol Biol.2016;23:899.

53. Walls AC, Tortorici MA, Bosch BJ, Frenz B, Rottier PJ, Di-Maio F, et al. Cryo-electron microscopy structure of a coronavirus spike glycoprotein trimer. Nature. 2016;531:114-117.

54. Kirchdoerfer RN, Cottrell CA, Wang N, Pallesen J, Yassine HM, Turner HL, et al. Pre-fusion structure of a human coronavirus spike protein. Nature. 2016;531:118-121.

55. Yuan Y, Cao D, Zhang Y, Ma J, Qi J, Wang Q, et al. Cryo-EM structures of MERS-CoV and SARS-CoV spike glycoproteins reveal the dynamic receptor binding domains. Nat Commun. 2017;8:15092.

56. Shang J, Zheng Y, Yang Y, Liu C, Geng Q, Luo C, et al. Cryo-EM structure of infectious bronchitis coronavirus spike protein reveals structural and functional evolution of coronavirus spike proteins. PLoS Pathog. 2018;14:e1007009.

57. Shang J, Zheng Y, Yang Y, Liu C, Geng Q, Tai W, Li F, et al. Cryo-electron microscopy structure of porcine deltacoronavirus spike protein in the prefusion state. J Virol. 2018;92: e01556-17.

58. Song W, Gui M, Wang X, Xiang Y, et al. Cryo-EM structure of the SARS coronavirus spike glycoprotein in complex with its host cell receptor ACE2. PLoS Pathog. 2018;14:1007236.

59. Li F, Berardi M, Li WH, Farzan M, Dormitzer PR, Harrison SC, et al. Conformational states of the severe acute respiratory syndrome coronavirus spike protein ectodomain. J Virol. 2006;80:6794-800.

60. Walls AC, Tortorici MA, Snijder J, et al. Tectonic conformational changes of a coronavirus spike glycoprotein promote membrane fusion. Proc Natl Acad Sci USA. 2017;114:11157-11162.

61. Heald-Sargent T, Gallagher T, et al. The coronavirus spike protein and acquisition of fusion competence. Virus.2012;4: 557-580.

62. Millet JK, Whittaker G. Host cell entry of Middle East respiratory syndrome coronavirus after two-step, furin-mediated activation of the spike protein. Proc Natl Acad Sci USA. 2014; 111:15214-15219.

63. Chen Z, Pei D, Jiang L, Song Y, Wang J, Wang H, Qiu M, et al. Antigenicity analysis of different regions of the severe acute respiratory syndrome coronavirus nucleocapsid protein. Clin Chem.2004;50:988-995.

64. Lin X, Gong Z, Xiao Z, Xiong J, Fan B, Liu J, et al. Novel coronavirus pneumonia outbreak in 2019: computed tomographic findings in two cases. Korean J Radiol. 2020;21: 365-368.

65. Cui L, Wang H, Ji Y, Yang J, Xu S, Huang X, Guo D, et al. The nucleocapsid protein of coronaviruses acts as a viral suppressor of RNA silencing in mammalian cells. J Virol. 2015; 89:9029-9043.

66. Ali PSS, John J, Selvaraj M, Kek TL, Salleh MZ, et al.Nodamura virus B2 amino terminal domain sensitivity to small interfering RNA. Microbiol Immunol. 2015;59:299-304.

67. Simmons G, Zmora P, Gierer S, et al. Proteolytic activation of the SARS-coronavirus spike protein: cutting enzymes at the cutting edge of antiviral research. Antivir Res. 2013;100:605-614.

68. Matsuyama S, Nagata N, Shirato K, Kawase M, Takeda M, et al.Efficient activation of the severe acute respiratory syndrome coronavirus spike protein by the transmembrane protease TMPRSS2. J Virol. 2010;84:12658-12664.

69. Bertram S, Glowacka I, Müller MA, Lavender H, Gnirss K, Nehlmeier I, et al. Cleavage and activation of the severe acute respiratory syndrome coronavirus spike protein by human airway trypsin-like protease. $J$ Virol. 2011;85:13363-13372.

70. Belouzard S, Chu VC, Whittaker G. R. Activation of the SARS coronavirus spike protein via sequential proteolytic cleavage at two distinct sites. Proceed Nati Acad Sci. 2009;106:5871-5876. 
71. Kuba K, Imai Y, Rao S, Gao H, Guo F, Guan B, et al. A crucial role of angiotensin converting enzyme 2 (ACE2) in SARS coronavirus-induced lung injury. Nat Med. 2005;11:875-879.

72. Glowacka I, Bertram S, Muller MA, Allen P, Soilleux E, Pfeerle S, et al. Evidence that TMPRSS2 Activates the Severe Acute Respiratory Syndrome Coronavirus Spike Protein for Membrane Fusion and Reduces Viral Control by the Humoral Immune Response. J Virol.2011;85:4122-4134.

73. Heurich A, Hofmann-Winkler H, Gierer S, Liepold T, Jahn O, et al. TMPRSS2 and ADAM17 cleave ACE2 differentially and only proteolysis by TMPRSS2 augments entry driven by the severe acute respiratory syndrome coronavirus spike protein. J Virol. 2014;88:1293-1307.

74. Shulla A, Heald-Sargent T, Subramanya G, Zhao J, Perlman S, Gallagher TA. Transmembrane Serine Protease Is Linked to the Severe Acute Respiratory Syndrome Coronavirus Receptor and Activates Virus Entry. J Virol. 2011;85:873-882.

75. Rabi FA, Al-Zoubi MS, Kasasbeh GA, Salameh DM, et al.SARS-CoV-2 and Coronavirus Disease 2019: What We Know So Far.Pathogens. 2020;9:231.

76. Xu Y, Lou Z, Liu Y, Pang H, Tien P, Gao GF, et al. Crystal structure of severe acute respiratory syndrome coronavirus spike protein fusion core. J Biol Chem. 2004;279:49414-49419.

77. Tortorici MA, Veesler D. Structural insights into coronavirus entry. Adv Virus Res. 2019;105: 93-116.

78. Bosch BJ, van der Zee R, de Haan CA, Rottier PJ. The coronavirus spike protein is a class I virus fusion protein: structural and functional characterization of the fusion core complex. J Virol. 2003;77:8801-8811.

79. Burkard C, Verheije MH, Wicht O, van Kasteren SI, van Kuppeveld FJ, et al. Coronavirus cell entry occurs through the endo-/lysosomal pathway in a proteolysis-dependent manner. PLoS Pathog. 2014;10.

80. Park JE, Li K, Barlan A, Fehr A, Perlman S, et al.Proteolytic processing of Middle East respiratory syndrome coronavirus spikes expands virus tropism. Proceed Natio Acad Sci.2016;113:12262-12267.

81. Gui M, Song W, Zhou H, Xu J, Chen S, Xiang Y, et al. Cryo-electron microscopy structures of the SARSCoV spike glycoprotein reveal a prerequisite conformational state for receptor binding. Cell Res.2017;27:119129.

82. Pallesen J, Wang N, Corbett KS, Wrapp D, Kirchdoerfer RN, et al. PImmunogenicity and structures of a rationally designed prefusion MERS-CoV spike antigen. Proceed Natio Acad Sci.2017;114:E7348-E7357.

83. Madu IG, Roth SL, Belouzard S Whittaker GR. Characterization of a highly conserved domain within the severe acute respiratory syndrome coronavirus spike protein S2 domain with characteristics of a viral fusion peptide. J Virol. 2009;83:7411-7421.

84. Li W, Moore MJ, Vasilieva N, Sui J, Wong SK, Berne MA, et al. Angiotensin-converting enzyme 2 is a functional receptor for the SARS coronavirus. Nature. 2003;426:450-454.

85. Hamming I, Timens W, Bulthuis MLC, Lely AT, Navis GJ, et al.Tissue distribution of ACE2 protein, the functional receptor for SARS coronavirus. A first step in understanding SARS pathogenesis. $J$ Pathol: $J$ Pathol Soc Great Brit Ireland. 2004;203:631-637.

86. Young BE, Ong SWX, Kalimuddin S, Low J G, et al.Epidemiologic features and clinical course of patients infected with SARS-CoV-2 in Singapore. JAMA. 2020.

87. Walls AC, Xiong X, Park YJ, Tortorici MA, et al. Unexpected receptor functional mimicry elucidates activation of coronavirus fusion. Cell. 2019;176:1026-1039.

88. Xiong X, Tortorici MA, Snijder J, Yoshioka C, Walls AC, et al. Glycan shield and fusion activation of a deltacoronavirus spike glycoprotein fine-tuned for enteric infections. J Virol. 2018;92:e01628-17.

89. Lindenbach BD, Rice CM. Molecular biology of flaviviruses. Advan Virus Res. 2003;59:23-62. 
90. Rossen JWA, De Beer R, Godeke GJ, Raamsman MJB, Horzinek MC, et al. The viral spike protein is not involved in the polarized sorting of coronaviruses in epithelial cells. J Virol. 1998;72:497-503.

91. Yang Y, Liu C, Du L, Jiang S, Shi Z, et al. Two mutations were critical for bat-to-human transmission of Middle East respiratory syndrome coronavirus. J Virol. 2015;89:9119-9123.

92. Chen L, Xiong J, Bao L, Shi Y. Convalescent plasma as a potential therapy for COVID-19. Lancet Infect Dis. 2020.

93. Wang D, Hu B, Hu C, Zhu F, Liu X, Zhang J, et al. Clinical characteristics of 138 hospitalized patients with 2019 novel coronavirus-infected pneumonia in Wuhan, China. JAMA. 2020.

94. Cao B, Wang Y, Wen D, Liu W, Wang J, Fan G, et al. Complete reference from online. A Trial of Lopinavir-Ritonavir in Adults Hospitalized with Severe Covid-19. New Eng J Med. 2020.

95. Lim J, Jeon S, Shin HY, Kim MJ, Seong YM, Lee WJ, et al. Case of the Index Patient Who Caused Tertiary Transmission of Coronavirus Disease 2019 in Korea: The Application of Lopinavir/Ritonavir for the Treatment of COVID-19 Pneumonia Monitored by Quantitative RT-PCR.J Korean Med Sci. 2020;35:e79.

96. Dong L, Hu S, Gao J. Discovering drugs to treat coronavirus disease 2019 (COVID-19). Drug Discover Therap. 2020;14:58-60.

97. Colson P, Rolain JM, Lagier JC, Brouqui P, Raoult D. Chloroquine and hydroxychloroquine as available weapons to fight COVID-19. Inter J Antimicrob Agents. 2020.

98. Cortegiani A, Ingoglia G, Ippolito M, Giarratano A, Einav S. A systematic review on the efficacy and safety of chloroquine for the treatment of COVID-19. J Critical Care. 2020.

99. Gao J, Tian Z, Yang X. Breakthrough: Chloroquine phosphate has shown apparent efficacy in treatment of COVID-19 associated pneumonia in clinical studies. BioScience Trends. 2020.

100. Touret F, Lamballerie XD. Of chloroquine and COVID-19.Antiviral Res. 2020;177:104762.

101. Gautret P, Lagier JC, Parola P, Hoang VT, Meddeb L, Mailhe M, et al. Hydroxychloroquine and azithromycin as a treatment of COVID-19: results of an openlabel non-randomized clinical trial. Inter $J$ Antimicrob Agents. 2020.

102. Cheng Y, Wong R, Soo YO, et al. Use of convalescent plasma therapy in SARS patients in Hong Kong. Eur J Clin Microbiol Infect Dis. 2005;24:44-46.

103. Lai ST. Treatment of severe acute respiratory syndrome. Eur J Clin Microbiol Infect Dis. 2005;24:58391.

104. Soo YO, Cheng Y, Wong R, et al. Retrospective comparison of convalescent plasma with continuing high-dose methylprednisolone treatment in SARS patients. Clin Microbiol Infect.2004;10:676-78.

105. WHO. Use of convalescent whole blood or plasma collected from patients recovered from Ebola virus disease for transfusion, as an empirical treatment during outbreaks 2014. http://apps.who.int/iris/rest/bitstreams/604045/retrieve (accessed Feb 20, 2020).

106. Arabi Y, Balkhy H, Hajeer AH. Feasibility, safety, clinical, and laboratory effects of convalescent plasma therapy for patients with Middle East respiratory syndrome coronavirus infection: a study protocol. Springerplus. 2015;4:709.

107. Su B, Wang Y, Zhou R, Jiang T, Zhang H, Li Z, et al. Efficacy and tolerability of lopinavir/ritonavirand efavirenz-based initial antiretroviral therapy in HIV-1- infected patients in a tertiary care hospital in Beijing, China. Front Pharmacol. 2019;10:1472.

108. Chu CM, Cheng VCC, Hung IFN, Wong MML, Chan KH, Chan KS, et al. Role of lopinavir/ritonavir in the treatment of SARS: Initial virological and clinical findings. Thorax. 2004;59:252-256. 
109. Furuta Y, Komeno T, Nakamura T. Favipiravir (T-705), a broad spectrum inhibitor of viral RNA polymerase. Proc Jpn Acad, Ser B, Phys Biol Sci. 2007;93:449-463.

110. Delang L, Abdelnabi R, Neyts J. Favipiravir as a potential countermeasure against neglected and emerging RNA viruses.Antiviral Res. 2018;153:85-94.

111. News. http://www.szdsyy.com/News/0a6c1e58-e3d0-4cd1-867ad5524bc59cd6.html (accessed February 22, 2020). (in Chinese).

112. Stockman LJ, Bellamy R, Garner P. SARS: Systematic review of treatment effects. PLoS Med. 2006;3:e343.

113. News: Abidol and darunavir can effectively inhibit coronavirus http://www.sd.chinanews. com/2/2020/0205/70145.html (accessed February 21, 2020). (in Chinese).

114. Gordon CJ, Tchesnokov EP, Feng JY, Porter DP, Gotte M. The antiviral compound remdesivir potently inhibits RNA-dependent RNA polymerase from Middle East respiratory syndrome coronavirus. J Biol Chem. 2020 .

115. Sheahan TP, Sims AC, Leist SR, et al. Comparative therapeutic efficacy of remdesivir and combination lopinavir, ritonavir, and interferon beta against MERS-CoV. Nat Commun. 2020;11:222.

116. Wang C, Horby PW, Hayden FG, Gao GF. A novel coronavirus outbreak of global health concern. Lancet. 2020;395:470-473.

117. Holshue ML, DeBolt C, Lindquist S, et al. First case of 2019 novel coronavirus in the United States. $N$ Engl J Med. 2020.

118. Wang M, Cao R, Zhang L, et al. Remdesivir and chloroquine effectively inhibit the recently emerged novel coronavirus (2019- nCoV) in vitro. Cell Res. 2020.

119. De-Wit E, Feldmann F, Cronin J, Jordan R, Okumura A, Thomas T. Prophylactic and therapeutic remdesivir (GS-5734) treatment in the rhesus macaque model of MERS-CoV infection. Proc Natl Acad Sci USA. 2020.

120. Lai CC, Shih TP, Ko WC, Tang HJ, Hsueh PR. Severe acute respiratory syndrome coronavirus 2 (SARSCoV-2) and coronavirus disease-2019 (COVID-19): The epidemic and the challenges. Intern J Antimicrob Agents. 2020;55:105924.

121. Savarino A, Di-Trani L, Donatelli I, Cauda R, Cassone A. New insights into the antiviral effects of chloroquine. Lancet Infect Dis. 2006;6:67-9.

122. Biot C, Daher W, Chavain N, Fandeur T, Khalife J, Dive D, et al. Design and synthesis of hydroxyferroquine derivatives with antimalarial and antiviral activities. $J$ Med Chem.2006;49:2845-2849.

123. Miller DK, Lenard J. Antihistaminics, local anesthetics, and other amines as antiviral agents. Proc Natl Acad Sci USA.1981;78:3605-3609.

124. Shimizu Y, Yamamoto S, Homma M, Ishida N. Effect of chloroquine on the growth of animal viruses. Arch fur die Gesamte Virusforschung. 1972;36:93-104.

125. Inglot AD. Comparison of the antiviral activity in vitro of some non-steroidal anti-inflammatory drugs. J Gen Virol.1969;4:203-214.

126. Yan Y, Zou Z, Sun Y, Li X, Xu KF, Wei Y, et al. Anti-malaria drug chloroquine is highly effective in treating avian influenza A H5N1 virus infection in an animal model. Cell Res. 2013;23:300-302.

127. Rolain JM, Colson P, Raoult D. Recycling of chloroquine and its hydroxyl analogue to face bacterial, fungal and viral infections in the 21st century. Int J Antimicrob Agents. 2007;30:297-308. 
128. Keyaerts E, Vijgen L, Maes P, Neyts J, Ranst MV. In vitroinhibition of severe acute respiratory syndrome coronavirus by chloroquine. Biochem Biophys Res Commun. 2004;323, 264-268.

129. Savarino A, Boelaert JR, Cassone A, Majori G, Cauda R. Effects of chloroquine on viral infections: an old drug against today's diseases. Lancet Infect Dis. 2003;3:722-727.

130. Marmor MF, Kellner U, Lai TY, Melles RB, Mieler WF. American Academy of Ophthalmology. Recommendations on Screening for Chloroquine and Hydroxychloroquine Retinopathy (2016 Revision). Ophthalmology. 2016;123:1386-94.

131. Frisk-Holmberg M, Bergqvist Y, Englund U. Chloroquine intoxication [letter]. Br J Clin Pharmacol. 1983;15:502-503.

\section{Hosted file}

FIGURE.docx available at https://authorea.com/users/331710/articles/458291-novel-coronavirus-disease-2019-review-on-ncovid-19 